\title{
Adiponectin in eutrophic and obese children as a biomarker to predict metabolic syndrome and each of its components
}

Miguel Klünder-Klünder ${ }^{1 \dagger}$, Samuel Flores-Huerta ${ }^{1 \dagger}$, Rebeca García-Macedo $^{2}$, Jesús Peralta-Romero ${ }^{2}$ and Miguel $\mathrm{Cruz}^{2^{*}}$

\begin{abstract}
Background: Obesity is associated with the rise of noncommunicable diseases worldwide. The pathophysiology behind this disease involves the increase of adipose tissue, being inversely related to adiponectin, but directly related to insulin resistance and metabolic syndrome (MetS). Therefore, this study aimed to determine the relationship between adiponectin levels with each component of MetS in eutrophic and obese Mexican children.

Methods: A cross sectional study was conducted in 190 school-age children classified as obese and 196 classified as eutrophic. Adiponectin, glucose, insulin, high density lipoprotein cholesterol (HDL-C) and triglycerides were determined from a fasting blood sample. Height, weight, waist circumference, systolic and diastolic blood pressures (BP) were measured; MetS was evaluated with the IDF definition. The study groups were divided according to tertiles of adiponectin, using the higher concentration as a reference. Linear regression analysis was used to assess the association between adiponectin and components of the MetS. Finally, stepwise forward multiple logistic regression analysis controlling for age, gender, basal HOMA-IR values and BMI was performed to determine the odds ratio of developing MetS according to adiponectin tertiles.

Results: Anthropometric and metabolic measurements were statistically different between eutrophic and obese children with and without MetS $(P<0.001)$. The prevalence of MetS in obese populations was $13 \%$. Adiponectin concentrations were $15.5 \pm 6.1,12.0 \pm 4.8,12.4 \pm 4.9$ and $9.4 \pm 2.8 \mu \mathrm{g} / \mathrm{mL}$ for eutrophic and obese subjects, obese without MetS, and obese with MetS, respectively $(P<0.001)$. Obese children with low values of adiponectin exhibited a higher frequency of MetS components: abdominal obesity, 49\%; high systolic BP, 3\%; high diastolic BP, 2\%; impaired fasting glucose, 17\%; hypertriglyceridemia, 31\%; and low HDL-C values, 42\%. Adjusted odds ratio of presenting MetS according to adiponectin categories was $10.9(95 \% \mathrm{Cl} 2.05 ; 48.16)$ when the first tertile was compared with the third.
\end{abstract}

Conclusion: In this sample of eutrophic and obese Mexican children we found that adiponectin concentrations and MetS components have an inversely proportional relationship, which supports the idea that this hormone could be a biomarker for identifying individuals with risk of developing MetS.

Keywords: Obesity, Adiponectin, Child, Insulin resistance, Metabolic syndrome, Biomarker

\footnotetext{
* Correspondence: mcruzl@yahoo.com

${ }^{\dagger}$ Equal contributors

${ }^{2}$ Medical Research Unit in Biochemistry, UMAE Bernardo Sepúlveda, Centro

Médico Nacional Siglo XXI, IMSS, Mexico City, Mexico

Full list of author information is available at the end of the article
} 


\section{Background}

During the last three decades, obesity has emerged worldwide as an epidemic affecting all ages and socioeconomic levels. In Mexico, the prevalence of obesity in school-age children has an upward trend [1]. The Mexican National Health and Nutrition Survey 2006 reported an increase of $77 \%$ and $47 \%$ in boys and girls respectively, between 1999 and 2006 [2]. The childhood obesity epidemic has led to a parallel rise in the prevalence of pediatric forms of chronic illnesses such as type 2 diabetes (T2D) and high blood pressure (BP), which in the recent past were typically adult diseases $[3,4]$.

Despite the fact that the classification of metabolic syndrome (MetS) has several limitations, for instance the use of categorical criteria in each of its components $[5,6]$, it is a useful clinical tool to identify individuals with risk of developing diseases associated with obesity.

Currently, the pathophysiology behind this syndrome begins with the fact that the adipose tissue, visceral and ectopic, functions as an endocrine gland producing an imbalance between pro and anti-inflammatory cytokines. Pro-inflammatory cytokines such as TNF- $\alpha$, IL-6, IL-1 $\beta$, and PAI-1, increase; while adiponectin, an anti-inflammatory cytokine, decreases [7]. This imbalance elicits lowdegree systemic inflammation associated with insulin resistance [8]. Owing to that after weight reduction, adiponectin increases, improving insulin sensitivity throughout the body [9-12], its plasmatic concentration has been proposed as a candidate biomarker to identify metabolic alterations including those of MetS [13-15]. However, in children this adiponectin role still remains controversial $[16,17]$.

Therefore, the aim of this study was to determine the relationship between plasmatic adiponectin levels and MetS components in eutrophic and obese children, and to assess whether this hormone could be a biomarker for MetS in Mexican children.

\section{Methods}

This epidemiological study was conducted from November 2007 to December 2010 in nine middle-class schools of Mexico City. Prior to the study, ethical clearance was obtained by both the ethics and research institutional boards of the Hospital Infantil de México "Federico Gómez" and school authorities; likewise, written informed consent was obtained from the participants and their parents in each of the two stages of the study. The first stage aimed to identify obese school-age children. For this purpose and following international anthropometric guidelines [18], a trained team of nurses measured children's weight and height without shoes and wearing light clothing. Weight was taken using a digital scale (Seca, Hamburg, Germany) to the nearest $0.1 \mathrm{~kg}$; height was measured using a Seca 225 stadiometer to the nearest $0.1 \mathrm{~cm}$. This screening was performed in 1,441 children between 6 and 12 years of age, and eutrophic or obese status was assessed using BMI percentiles according to the 2000 Centers for Disease Control and Prevention reference (Atlanta, GA, USA) [19].

Eutrophic status was considered when BMI was between 25th and 75th percentile and obese when the BMI was $>95$ th percentile for the child's age and gender. Because the purpose of the study was assessing if plasmatic adiponectin levels categorized in tertiles were able to identify a certain profile as healthy or at risk, the sample was designed to have contrasting nutritional status groups, either normal or obese. In order to fulfill the study's aims, individuals between normal and obese (BMI $>75$ th pc $<95$ th pc) or between normal and malnourished (BMI $<25$ th pc) were purposefully excluded.

Of all the participants, 286 were obese (19.9\%), 20 of them did not meet the inclusion criteria and 59 did not accept to participate. In 190 out of 207 individuals complete blood samples were collected. According to our criteria, there were 524 eutrophic children of which 250 were invited to participate and 209 accepted. In 196, whole blood samples were drawn. Those who selfreported as having an acute infectious disease, suffering from chronic illness such as allergies and autoimmune diseases that could alter cytokines patterns, or those who were participating in a weight reduction program were excluded.

In the second stage, BP was obtained by auscultatory method using a sphygmomanometer (ALPK2, Tokyo, Japan) with appropriate cuff size for arm length, following North American guidelines issued in 2004 [20]. Four $\mathrm{BP}$ readings were taken for each participant on the right arm in a sitting position, resting 1 minute between each measurement. The mean of the last three readings was considered the final level of BP. Waist circumference (WC) was measured at the midpoint between the lowest rib and the iliac crest after a normal exhalation with children in the standing position. A fasting blood sample was used to determine insulin by chemiluminescence immunoassay (IMMULITE 2000, Euro, DPC, Llanberis, UK), glucose, total cholesterol, low-density lipoprotein cholesterol (LDL-C), high-density lipoprotein cholesterol (HDL-C), and triglycerides (ILAB 300, Instrumentation Laboratory, Barcelona, Spain). Intra and inter assay coefficients of variation $(\mathrm{CV})$ values were $<5 \%$. Total adiponectin was determined by ELISA method (Human Adiponectin ELISA Kit, Millipore, St. Charles, MO, USA), in which the mean of the minimum detectable concentration was $0.78 \mathrm{ng} / \mathrm{mL}$. Intra- and inter assay $\mathrm{CV}$ were $<7.4$ and $<8.4 \%$, respectively. All analyses were performed during the 2-5 days following the blood sample extraction. HOMA-IR was obtained by the following equation: [fasting glucose $(\mathrm{mg} / \mathrm{dL}) \mathrm{x}$ fasting insulin $(\mu \mathrm{U} / \mathrm{mL}) / 405]$. 
A 3.4 HOMA-IR value was the cut-off point to accept IR, which corresponds to the $90^{\text {th }}$ percentile in a population of healthy children [21].

\section{Definition of MetS}

MetS was defined according to guidelines of the International Diabetes Federation (IDF) [22], with the exception of BP in which case the criterion used was according to the North American Task Force guidelines [20]. Therefore, MetS was diagnosed by abdominal obesity (WC $\geq 90^{\text {th }}$ percentile for child's age, gender and ethnic origin) [23,24] and the presence of two or more other clinical features: triglycerides $\geq 150 \mathrm{mg} / \mathrm{dL}$; HDL-C $\leq 40 \mathrm{mg} / \mathrm{dL}$, BP systolic and/or diastolic $\geq 90^{\text {th }}$ percentile for child's age, gender and height; fasting glucose $\geq 100 \mathrm{mg} / \mathrm{dL}$.

\section{Statistical analysis}

Anthropometric and metabolic data were tested for normal distribution using skewness and kurtosis. Comparisons between continuous variables and groups were performed with Student $t$ test or Mann-Whitney U test according to data distribution. In order to assess the effect of adiponectin on each of the MetS components, insulin and HOMA-IR, this hormone was categorized in tertiles, and obese individuals were reclassified to those with or without MetS. Differences in metabolic features between adiponectin tertile categories were obtained using linear regression analysis. The prevalence of each component of MetS was obtained within each of the adiponectin tertiles. To assess the odds of developing MetS, these were compared in whole population according to the previously mentioned adiponectin tertile categories using logistic regression analysis and adjusted by BMI and sex and age. $\mathrm{P}<0.05$ was accepted as statistically significant. Data were processed with STATA, SE v.11.0, and EPIINFO 3.3.2 according to the 2000 CDC reference [19].

\section{Results}

Anthropometric features, blood pressure, metabolic profile and adiponectin concentrations of eutrophic and obese children with or without MetS are shown in Table 1. Age range of the participants was 6-12 years

Table 1 Anthropometric, clinical and metabolic characteristics in eutrophic and obese children with and without MetS

\begin{tabular}{|c|c|c|c|c|c|c|}
\hline \multirow[t]{4}{*}{ Characteristics } & \multirow{4}{*}{$\begin{array}{l}\text { Eutrophic } \\
\mathbf{n}=196 \\
\text { Mean } \pm \text { SD }\end{array}$} & \multirow[t]{2}{*}{ Obese } & \multirow[b]{4}{*}{$P^{d}$} & \multicolumn{2}{|l|}{ Obese } & \multirow[b]{4}{*}{$\mathrm{P}^{\mathrm{e}}$} \\
\hline & & & & Without MetS & With MetS & \\
\hline & & \multirow{2}{*}{$\begin{array}{l}\mathbf{n}=190 \\
\text { Mean } \pm \text { SD }\end{array}$} & & $n=166$ & $\mathrm{n}=24$ & \\
\hline & & & & Mean \pm SD & Mean \pm SD & \\
\hline Age (years) & $9.4 \pm 1.8$ & $9.6 \pm 1.8$ & 0.368 & $9.6 \pm 1.9$ & $9.4 \pm 1.4$ & 0.623 \\
\hline \multicolumn{7}{|c|}{ Anthropometric measurements } \\
\hline WC $(\mathrm{cm})$ & $57.8 \pm 4.9$ & $79.0 \pm 9.1$ & $<0.001$ & $78.3 \pm 9.2$ & $83.5 \pm 6.5$ & 0.004 \\
\hline $\mathrm{BMI}\left(\mathrm{kg} / \mathrm{m}^{2}\right)$ & $16.4 \pm 1.3$ & $24.5 \pm 2.7$ & $<0.001$ & $24.3 \pm 2.8$ & $25.8 \pm 2.5$ & 0.009 \\
\hline BMI percentile ${ }^{a}$ & $46.1 \pm 18.2$ & $97.4 \pm 1.3$ & $<0.001$ & $97.2 \pm 1.3$ & $98.3 \pm 0.9$ & $<0.001$ \\
\hline \multicolumn{7}{|c|}{ Blood pressure (mm/Hg) } \\
\hline SBP & $88.6 \pm 7.8$ & $97.8 \pm 8.8$ & $<0.001$ & $97.1 \pm 8.2$ & $101.3 \pm 10.8$ & 0.028 \\
\hline SBP percentile & $17.3 \pm 18.2$ & $33.8 \pm 22.9$ & $<0.001$ & $32.0 \pm 21.1$ & $43.2 \pm 30.6$ & 0.037 \\
\hline Diastolic & $55.8 \pm 7.1$ & $62.2 \pm 7.6$ & $<0.001$ & $61.4 \pm 7.2$ & $65.9 \pm 7.9$ & 0.009 \\
\hline DBP percentile & $37.7 \pm 20.9$ & $53.6 \pm 21.5$ & $<0.001$ & $51.7 \pm 20.5$ & $63.5 \pm 22.3$ & 0.021 \\
\hline \multicolumn{7}{|l|}{ Metabolic parameters* } \\
\hline Glucose (mg/dL) & $90.0(57.0-14.0)$ & $90.0(58.0-108.0)$ & 0.794 & 90.0 (58.0-108.0) & $94.0(54.0-107.0)$ & 0.090 \\
\hline Insulin (mU/mL) & $4.3(1.9-19.5)$ & $9.3(2.0-68.0)$ & $<0.001$ & $9.1(2.0-55.2)$ & $14.1(3.8-68.0)$ & $<0.001$ \\
\hline HOMA-IR & $1.0(0.3-5.0)$ & $2.0(0.4-13.9)$ & $<0.001$ & $2.0(0.4-13.9)$ & $3.5(0.7-11.2)$ & $<0.001$ \\
\hline TGs (mg/dL) & $72.0(22.5-193.5)$ & $106.5(30.0-366.0)$ & $<0.001$ & $104.0(30.0-366.0)$ & $166.0(72.9-255.0)$ & $<0.001$ \\
\hline $\mathrm{HDL}-\mathrm{C}(\mathrm{mg} / \mathrm{dL})$ & $53.0(21.0-110.0)$ & $44.0(9.0-82.0)$ & $<0.001$ & $45.0(20.0-82.0)$ & $36.0(9.0-51.0)$ & $<0.001$ \\
\hline \multicolumn{7}{|l|}{ Inflammatory* } \\
\hline Adiponectin $(\mu \mathrm{g} / \mathrm{mL})$ & $14.5(3.9-38.8)$ & $11.5(1.4-27.5)$ & $<0.001$ & $12.2(1.4-27.5)$ & $8.4(4.2-15.3)$ & 0.003 \\
\hline
\end{tabular}

${ }^{a}$ According to CDC 2000.

${ }^{\mathrm{b}}$ According to The National High Blood Pressure Education Program.

CHOMA-IR: [(fasting glucose $(\mathrm{mg} / \mathrm{dL}))($ fasting insulin $(\mu \mathrm{U} / \mathrm{mL})) / 405)]$.

${ }^{d} t$ test $p$ value for means or Mann Whitney $U$ test for medians: eutrophic vs. eutrophic obese, ${ }^{e}$ Obese without MetS vs. obese with MetS.

*Median (min-max).

MetS, metabolic syndrome; WC, waist circumference; BMI, body mass index; SBP, systolic blood pressure; DBP, diastolic blood pressure; TGs, triglycerides; HDL-C, high-density lipoprotein cholesterol; MetS, metabolic syndrome. 


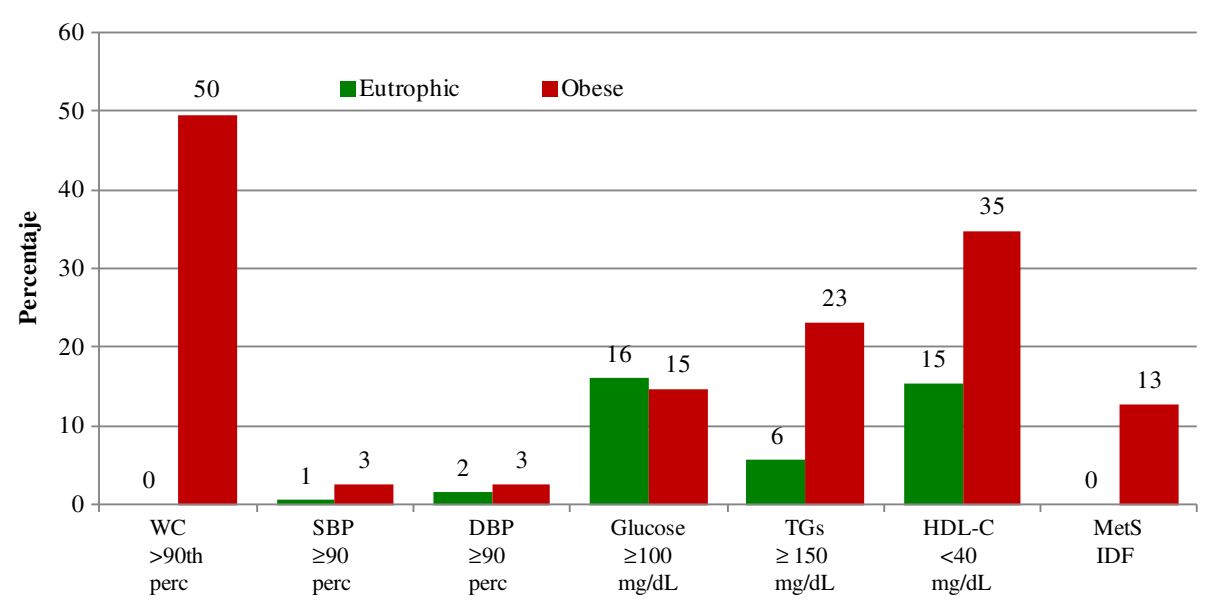

Figure 1 Prevalence of metabolic syndrome components by nutritional status. WC, waist circumference; SBP, systolic blood pressure; DBP, diastolic blood pressure; TGs, triglycerides; HDL-C, high-density lipoprotein cholesterol.

and the prevalence of MetS in the obese population was $\sim 13 \%$. BMI was different between eutrophic and obese participants and also between obese children with or without MetS ( $\mathrm{P}=0.004)$. BP (systolic and diastolic) values and percentiles were different between eutrophic and obese children $(\mathrm{P}<0.001)$ and also between children with or without MetS $(\mathrm{P}<0.05)$.

In terms of metabolic variables, obese children with MetS exhibited higher values of these variables than obese children without MetS and eutrophic children. Glucose values were not different between groups, but insulin concentrations increased significantly in obese children and especially in obese children with MetS $(\mathrm{P}<0.001)$. HOMA-IR values within the obese group with MetS were higher than those for the other groups $(\mathrm{P}<0.001)$. A similar relationship was observed with triglycerides $(\mathrm{P}<0.001)$.
Another parameter that differed was HDL-C, in which case the obese group with MetS showed the lowest values $(\mathrm{P}<0.001)$. Adiponectin levels in eutrophic children were higher compared with the obese group $(\mathrm{P}<0.001)$. Interestingly, lower concentrations of adiponectin were observed in the obese with MetS compared with obese without Met $S(\mathrm{P}=0.003)$.

Figures 1 and 2, show the prevalence of MetS and each of its altered components, according to nutritional status and adiponectin concentration. Figure 1 demonstrates that none of the eutrophic children had MetS showing a low prevalence in fasting glucose, HDL-C, and triglyceride alterations. Likewise, none of them had altered waist circumference and virtually no impairment in BP was shown. In contrast, $13 \%$ of the obese children had MetS. The most prevalent alterations in the obese group were

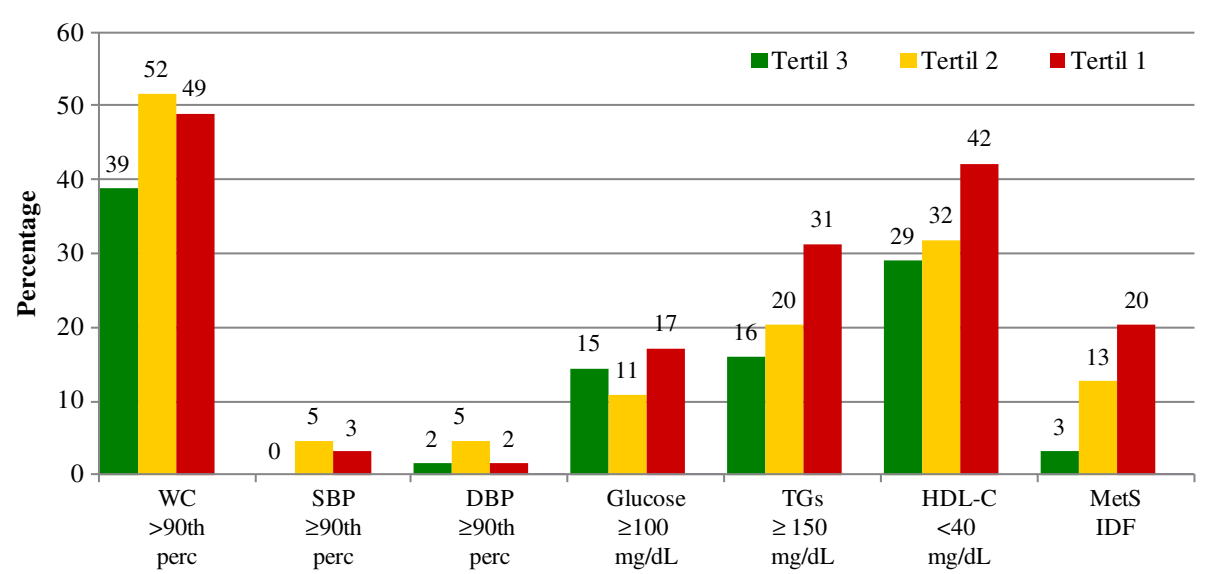

Figure 2 Prevalence of metabolic syndrome components in obese children, according to adiponectin tertile. WC, waist circumference; SBP, systolic blood pressure; DBP, diastolic blood pressure; TGs, triglycerides; HDL-C, high-density lipoprotein cholesterol. 
Table 2 Insulin resistance and MetS components according to level of adiponectin, in eutrophic and obese children and adolescents

\begin{tabular}{|c|c|c|c|c|c|c|}
\hline & \multicolumn{6}{|c|}{ Adiponectin tertile (values) } \\
\hline & \multicolumn{3}{|c|}{ Eutrophic subjects $(n=196)$} & \multicolumn{3}{|c|}{ Obese subjects $(n=190)$} \\
\hline & 3 & 2 & 1 & 3 & 2 & 1 \\
\hline Outcome variables & $(17.6-38.8)$ & $(12.6-17.5)$ & $(3.9-12.5)$ & $(13.4-27.5)$ & $(9.6-13.3)$ & $(1.4-9.5)$ \\
\hline \multicolumn{7}{|l|}{ Insulin resistance } \\
\hline \multicolumn{7}{|c|}{ Fasting insulin $(\mu \mathrm{m} / \mathrm{mL})$} \\
\hline Coefficient & Referent & 0.9 & 1.1 & Referent & 3.3 & 3.4 \\
\hline $95 \% \mathrm{Cl}$ & - & $-0.1 ; 1.9$ & $0.1 ; 2.1$ & - & $-0.1 ; 6.5$ & $0.2 ; 6.7$ \\
\hline$P$ & - & 0.083 & 0.032 & - & 0.053 & 0.039 \\
\hline \multicolumn{7}{|l|}{ HOMA-IR } \\
\hline Coefficient & Referent & 0.2 & 0.3 & Referent & 0.6 & 0.8 \\
\hline $95 \% \mathrm{Cl}$ & - & $-0.1 ; 0.4$ & $0.1 ; 0.5$ & - & $-0.2 ; 1.3$ & $0.1 ; 1.6$ \\
\hline$P$ & - & 0.123 & 0.035 & - & 0.126 & 0.022 \\
\hline \multicolumn{7}{|c|}{ Components of MetS } \\
\hline \multicolumn{7}{|l|}{ WC (cm) } \\
\hline Coefficient & Referent & 0.9 & 3.1 & Referent & 4.9 & 5.9 \\
\hline $95 \% \mathrm{Cl}$ & - & $-0.6 ; 2.4$ & $1.6 ; 4.6$ & - & $2.1 ; 7.7$ & $3.1 ; 8.7$ \\
\hline$P$ & - & 0.229 & $<0.001$ & - & 0.001 & $<0.001$ \\
\hline \multicolumn{7}{|c|}{ Blood pressure $(\mathrm{mmHg})$} \\
\hline \multicolumn{7}{|l|}{ SBP } \\
\hline Coefficient & Referent & 0.8 & 1.9 & Referent & 3.8 & 4.5 \\
\hline $95 \% \mathrm{Cl}$ & - & $-1.8 ; 3.5$ & $-0.8 ; 4.5$ & - & $0.9 ; 6.7$ & $1.6 ; 7.3$ \\
\hline$P$ & - & 0.538 & 0.168 & - & 0.010 & 0.002 \\
\hline \multicolumn{7}{|l|}{ DBP } \\
\hline Coefficient & Referent & 1.6 & 2.5 & Referent & 1.7 & 0.9 \\
\hline $95 \% \mathrm{Cl}$ & - & $-0.9 ; 4.0$ & $0.1 ; 5.0$ & - & $-1.0 ; 4.3$ & $-1.8 ; 3.5$ \\
\hline$P$ & - & 0.213 & 0.043 & - & 0.585 & 0.738 \\
\hline \multicolumn{7}{|l|}{ Glucose (mg/dL) } \\
\hline Coefficient & Referent & 0.1 & 0.5 & Referent & -0.4 & 3.9 \\
\hline $95 \% \mathrm{Cl}$ & - & $-3.6 ; 3.9$ & $-3.2 ; 4.3$ & - & $-3.9 ; 3.1$ & $-0.4 ; 7.4$ \\
\hline$P$ & - & 0.962 & 0.789 & - & 0.140 & 0.029 \\
\hline \multicolumn{7}{|l|}{ TGs (mg/dL) } \\
\hline Coefficient & Referent & -2.3 & 4.8 & Referent & 14.4 & 27.3 \\
\hline $95 \% \mathrm{Cl}$ & - & $-13.5 ; 8.9$ & $-6.2 ; 15.9$ & - & $-8.0 ; 36.8$ & $4.9 ; 49.6$ \\
\hline P & - & 0.931 & 0.391 & - & 0.206 & 0.017 \\
\hline \multicolumn{7}{|l|}{$\mathrm{HDL}-\mathrm{C}(\mathrm{mg} / \mathrm{dL})$} \\
\hline Coefficient & Referent & 2.2 & -0.3 & Referent & -1.3 & -4.1 \\
\hline $95 \% \mathrm{Cl}$ & - & $-2.4 ; 6.8$ & $-5.2 ; 4.5$ & - & $-5.3 ; 2.6$ & $-8.1 ; 0.1$ \\
\hline$P$ & - & 0.351 & 0.894 & - & 0.511 & 0.048 \\
\hline
\end{tabular}

Values obtained through linear regression and adjusted for gender and body mass index percentile.

Regression coefficients are change in outcome variables per tertile change in adiponectin concentration.

MetS, metabolic syndrome; WC, waist circumference; SBP, systolic blood pressure; DBP, diastolic blood pressure; TGs, triglycerides; HDL-C, high-density lipoprotein cholesterol. 
waist circumference (50\%), HDL-C (35\%), triglycerides $(23 \%)$, and fasting glucose (15\%). Children with altered $\mathrm{BP}$ were very few in both groups.

Figure 2 shows that prevalence of MetS components increase as adiponectin concentrations decrease in obese children. When adiponectin values were in the first tertile, $31 \%$ of these children had hypertrigliceridemia and $42 \%$ had low HDL-C values, compared to children in the third tertile who presented $16 \%$ and $29 \%$, respectively.

Table 2 shows a trend of increasing insulin and HOMA-IR when adiponectin values decreased in eutrophic and obese children $(\mathrm{p}<0.05)$. Also, in obese children the appearance of the components of MetS was higher when adiponectin values were in the low tertile $(\mathrm{P}<0.05)$.

In obese children, WC and systolic BP increased when adiponectin decreased to the second tertile $(\mathrm{P}=0.001$; $\mathrm{P}=0.010$ ). Additionally, when adiponectin decreased to the low tertile, WC and systolic BP significantly increased; $5.9 \mathrm{~cm}$ in $\mathrm{WC}(\mathrm{P}<0.001)$, and $4.5 \mathrm{mmHg}$ in systolic blood pressure $(\mathrm{P}=0.002)$. Glucose increased $3.9 \mathrm{mg} / \mathrm{dL}(\mathrm{P}=0.029)$. Triglycerides increased 27.3 $\mathrm{mg} / \mathrm{dL}(\mathrm{P}=0.017)$, whereas HDL-C decreased $4.1 \mathrm{mg} / \mathrm{dL}$ $(\mathrm{P}=0.048)$.

Table 3 shows how the odds of developing MetS are higher when adiponectin levels are lower (adjusted for gender, age, BMI and HOMA-IR). When adiponectin is in the first tertile, the odds ratio of developing MetS is 10.3 compared with the third tertile (95\% CI 2.05; 48.16).

\section{Discussion}

Our study found that adiponectin levels are associated with MetS as a whole and with each of its components, mainly in obese children.

Considering the age of participants, some of them could be in the pubertal stage, especially girls who can enter this phase up to two years earlier than boys [25]. Unfortunately, the pubertal stage was not measured in the study, and we cannot discriminate the potential influence of sexual hormones on changes in adiponectin. However, in studies in which the pubertal stage has been controlled, results regarding the association between adiponectin and MetS are controversial. Some of them show that pubertal stage mediates the association between adiponectin and MetS [26,27], while others performed in Latin-American children did not find this observation $[14,28]$. In the present study, adiponectin concentration between boys and girls were similar with values of 12.8 and $13.3 \mu \mathrm{g} / \mathrm{mL}$, respectively $(\mathrm{p}=0.362)$.

Concerning the prevalence of $13 \%$ of MetS in obese children reported herein, and in order to properly locate this figure in relationship to others, we compared this prevalence with other studies in which the IDF
Table 3 Odds ratio of developing MetS according to adiponectin tertile value

\begin{tabular}{llll}
\hline Variable & OR & $\mathbf{9 5} \% \mathbf{C l}$ & $\mathbf{P}$ \\
\hline Gender (female) & 0.8 & $0.28 ; 2.46$ & 0.737 \\
Age (years) & 0.8 & $0.57 ; 1.12$ & 0.200 \\
BMI (percentile) & 2.0 & $1.20 ; 3.39$ & 0.008 \\
HOMA-IR & 1.4 & $1.10 ; 1.73$ & 0.006 \\
Adiponectin tertile* & & & \\
3 & 1 & - & - \\
2 & 4.8 & $0.84 ; 26.83$ & 0.078 \\
1 & 10.3 & $2.05 ; 48.16$ & 0.005 \\
\hline
\end{tabular}

Values obtained through logistic regression analysis, the final model included whole study population (obese and eutrophic children) adjusted for BMI (body mass index) percentile, gender, age and HOMA-IR values. *Tertiles used are according to nutritional status of each child as shown in Table 2.

definition was applied. In doing so, we found that the prevalence of MetS in obese children has a wide variation; in Greek children is $7.7 \%$, in Colombian is $11.7 \%$ [27,29], in Chinese and Spanish obese children is 27.6 and $19.6 \%$ respectively [30,31], and in another study on Mexican obese children the prevalence was 20\% [32]. Notwithstanding the same IDF definition of MetS, variation could be explained by the differences in the environment in which the children live.

It is noteworthy that independent of nutritional status of the children, when their adiponectin levels are in the lowest tertile all the components of MetS worsen; WC, diastolic BP, glucose, and triglycerides increase and HDL-C values decrease. On the other hand, when adiponectin levels are in the high tertiles, each component of MetS improves even in obese children, although it is not possible to say that these individuals are metabolically healthy.

A similar phenomenon but with less magnitude is observed in eutrophic children. Nowadays, we do not have a plausible way of explaining why adiponectin in eutrophic children decreases because they are not exposed to the inflammatory environment of obesity; however, eutrophic children with adiponectin concentrations in the low tertile have significantly higher values of HOMA IR, WC and diastolic BP than those in the high tertile. To our knowledge, the present work is the first to show that adiponectin also influences metabolic changes in eutrophic children, even after adjustment of adiponectin levels by BMI and gender.

In a recent bariatric surgery study that was made up of morbidly obese patients, the association between adiponectin genes and adiponectin expression was studied in eight patients with T2D and four control patients [33]. Adiponectin production was downregulated in obese patients but upregulated once obesity was reduced. Its production rose to levels close to the control group, 
suggesting that adiponectin expression is dysregulated with obesity. The versatile replenishment of this adipokine with weight loss supports the importance of using this cytokine as a biomarker in prevention programs as well as in treatment and control of diseases, especially T2D.

Although there are reports in which adiponectin has not been shown to be a useful biomarker for monitoring changes observed in MetS [16,17], evidence exists for postulating this cytokine as a biomarker of MetS and T2D in obese children and adolescents [13,14,34,35]. However, the molecular mechanisms that establish the relationship between adiponectin and metabolic derangements observed in clinical and epidemiological studies, have not been fully elucidated [36]. The most plausible explanation is that obesity, mainly visceral, is a condition in which there is an inflammatory state characterized by dysregulated production of adipokines in which antiinflammatory agents such as adiponectin decrease while pro-inflammatory cytokines such TNF $\alpha$ and IL-6, IL $1 \beta$ increase. Unfortunately pro- inflammatory cytokines were not measured in order to demonstrate their predominance, although at present, there is practically no discussion about the negative association between central obesity and adiponectin levels [37,38].

The use of adiponectin as a marker for MetS has already been shown in a 3-year prospective study where adiponectin levels in Korean children predicted the development of the MetS [26].

In addition to aforementioned limitations, it is necessary to highlight that this study is cross-sectional in design, which only permits associations but not causality to be established among different variables. Lastly, because the study was performed in an ethnically homogenous population in Mexico City its results may not apply to other populations. Despite these limitations, the negative association between adiponectin and the components of MetS suggest that these children have an imbalance in inflammatory adipokines.

\section{Conclusion}

In this sample of eutrophic and obese Mexican children, an inversely proportional relationship was found between adiponectin concentrations and MetS components, which supports the idea that this hormone could be a possible biomarker to identify individuals with risk of developing MetS.

\section{Competing interests}

The authors declare that they have no competing interests.

\section{Authors' contributions}

MKK participated in the design and coordination of the study, performed the statistical analysis, and revised the manuscript critically. SFH participated in the conception and design of the research question as well as in fieldwork supervision. RGM analyzed blood samples and revised the manuscript critically. JPR Obtained data and analyzed blood samples. All authors were involved in drafting the manuscript. All of them read and approved the final version of the manuscript.

\section{Acknowledgments}

The authors thank David Ramos and Araceli Mendez for technical assistance in biochemical and ELISA assays (Biochemistry Unit-IMSS), and also Sharon Morey, Scientific Communications, for help with editing the manuscript. We would also like to thank Mirena Astiazarán Osornio for her help in the translation of this paper. This work was supported by the CONACYT SALUD2005-C02-14412; Proyectos Estratégicos IMSS 2004-3601-0020; Hospital Infantil de México: Fondos Federales HIM/2008/003; Fundación IMSS, A.C., and the Gonzalo Rio Arronte Foundation. M. Cruz is a recipient of a Fundación IMSS Scholarship, Mexico.

\section{Author details}

${ }^{1}$ Community Health Research Department, Hospital Infantil de México Federico Gómez, Ministry of Health (SSA), Mexico City, Mexico. ${ }^{2}$ Medical Research Unit in Biochemistry, UMAE Bernardo Sepúlveda, Centro Médico Nacional Siglo XXI, IMSS, Mexico City, Mexico.

Received: 12 January 2012 Accepted: 22 January 2013

Published: 30 January 2013

\section{References}

1. Bonvecchio A, Safdie M, Monterrubio EA, Gust T, Villalpando S, Rivera JA: Overweight and obesity trends in Mexican children 2 to 18 years of age from 1988 to 2006. Salud Pub Mex 2009, 51(Suppl 4):S586-S594.

2. Olaiz-Fernández G, Rivera-Dommarco J, Shamah-Levy T, Rojas R, VillalpandoHernández S, Hernández-Avila M, Sepúlveda-Amor J: Encuesta Nacional de Salud y Nutrición 2006. Cuernavaca, México: Instituto Nacional de Salud Pública; 2006.

3. Cruz M, Torres M, Aguilar-Herrera B, Pérez-Johnston R, Guzmán-Juárez N, Aranda M, Kumate J: Type 2 diabetes mellitus in children: An increasing health problem in Mexico. J Pediatr Endocrinol Metab 2004, 17(2):183-190.

4. Flores-Huerta S, Klünder-Klünder M, Reyes-de-la-Cruz L, Santos JI: Increase in body mass index and waist circumference is associated with high blood pressure in children and adolescents in Mexico City. Arch Med Res 2009, 40(3):208-215.

5. Borch-Johnsen $\mathrm{K}$, Wareham N: The rise and fall of the metabolic syndrome. Diabetologia 2010, 53(4):597-599.

6. Simmons R, Alberti K, Gale E, Colagiuri S, Tuomilehto J, Qiao Q, Ramachandran A, Tajima N, Brajkovich Mirchov I, Ben-Nakhi A, et al: The metabolic syndrome: useful concept or clinical tool? Report of a WHO Expert Consultation. Diabetologia 2010, 53(4):600-605.

7. Valle M, Martos R, Gascón F, Cañete R, Zafra MA, Morales R: Low-grade systemic inflammation, hypoadiponectinemia and a high concentration of leptin are present in very young obese children, and correlate with metabolic syndrome. Diabetes \& Metabolism 2005, 31(1):55-62.

8. Körner A, Kratzsch J, Gausche R, Schaab M, Erbs S, Kiess W: New predictors of the metabolic syndrome in children: Role of adipocytokines. Pediatr Res 2007, 61:640-645.

9. Cambuli VM, Musiu MC, Incani M, Paderi M, Serpe R, Marras V, Cossu E, Cavallo MG, Mariotti S, Loche S, et al: Assessment of adiponectin and leptin as biomarkers of positive metabolic outcomes after lifestyle intervention in overweight and obese children. $J$ Clin Endocrinol Metab 2008, 93(8):3051-3057.

10. Kopp HP, Krzyzanowska K, Mohlig M, Spranger J, Pfeiffer AFH, Schernthaner $\mathrm{G}$ : Effects of marked weight loss on plasma levels of adiponectin, markers of chronic subclinical inflammation and insulin resistance in morbidly obese women. Int J Obes 2005, 29(7):766-771.

11. Martos-Moreno GA, Barrios V, Martinez G, Hawkins F, Argente J: Effect of weight loss on high-molecular weight adiponectin in obese children. Obesity 2010, 18(12):2288-2294.

12. Reinehr T, Roth C, Menke T, Andler W: Adiponectin before and after weight loss in obese children. J Clin Endocrinol Metab 2004, 89(8):3790-3794.

13. Gilardini L, McTernan PG, Girola A, da Silva NF, Alberti L, Kumar S, Invitti C: Adiponectin is a candidate marker of metabolic syndrome in obese children and adolescents. Atherosclerosis 2006, 189(2):401-407. 
14. Shaibi GQ, Cruz ML, Weigensberg MJ, Toledo-Corral CM, Lane CJ, Kelly LA, Davis JN, Koebnick C, Ventura EE, Roberts CK, et al: Adiponectin independently predicts metabolic syndrome in overweight Latino youth. J Clin Endocrinol Metab 2007, 92(5):1809-1813.

15. Shargorodsky M, Boaz M, Goldberg Y, Matas Z, Gavish D, Fux A, Wolfson N: Adiponectin and vascular properties in obese patients: is it a novel biomarker of early atherosclerosis? Int J Obes 2009, 33(5):553-558.

16. Cizmecioglu FM, Etiler N, Ergen A, Gormus U, Keser A, Hekim N, Hamzaoglu $\mathrm{O}$, Hatun S: Association of adiponectin, resistin and high sensitive CRP level with the metabolic syndrome in childhood and adolescence. Exp Clin Endocrinol Diabetes 2009, 117(EFirst):622-627.

17. Snehalatha C, Yamuna A, Ramachandran A: Plasma adiponectin does not correlate with insulin resistance and cardiometabolic variables in nondiabetic Asian Indian teenagers. Diabetes Care 2008, 31(12):2374-2379.

18. World Health Organization, Expert Committee: Physical status: The use and interpretation of anthropometry. In WHO technical report series 854 Geneva: Report of a WHO Expert Committee; 1995.

19. Kuczmarski RJ, Ogden CL, Guo SS, Grummer-Strawn LM, Flegal KM, Mei Z, Wei R, Curtin LR, Roche AF, Johnson CL: CDC growth charts for the United States: Methods and development. National Center for Health Statistics: Vital Health Stat 2000, 11(246):2002

20. National high blood pressure education program working group on high blood pressure in children and adolescents: The fourth report on the diagnosis, evaluation, and treatment of high blood pressure in children and adolescents. Pediatrics 2004, 114(Suppl 2):555-576.

21. García-Cuartero B, García-Lacalle C, Jiménez-Lobo C, González-Vergaz A, Calvo-Rey C, Alcázar-Villar MJ, Díaz-Martínez E: Índice HOMA y OUICKI insulina y péptido $C$ en niños sanos. Puntos de corte de riesgo cardiovascular. An Pediatr (Barc) 2007, 66(5):481-490

22. Zimmet P, Alberti G, Kaufman F, Tajima N, Silink M, Arslanian S, Wong G, Bennett $P$, Shaw J, Caprio S: The metabolic syndrome in children and adolescents. Lancet 2007, 369(9579):2059-2061.

23. Fernández JR, Redden DT, Pietrobelli A, Allison DL: Waist circumference percentiles in nationally representative samples of African-American, European-American, and Mexican-American children and adolescents. J Pediatr 2004, 145(4):439-444.

24. Klünder-Klünder M, Flores-Huerta S: Waist circumference values according to height percentiles: A proposal to evaluate abdominal obesity in Mexican children and adolescents between 6 and 16 years of age. Arch Med Res 2011, 42(6):515-522.

25. Kaplowitz PB, Slora EJ, Wasserman RC, Pedlow SE, Herman-Giddens ME: Earlier onset of puberty in girls: Relation to increased body mass index and race. Pediatrics 2001, 108(2):347-353.

26. Choi KM, Yannakoulia M, Park MS, Cho GJ, Kim JH, Lee SH, Hwang TG, Yang SJ, Kim TN, Yoo HJ, et al: Serum adipocyte fatty acid-binding protein, retinol-binding protein 4 , and adiponectin concentrations in relation to the development of the metabolic syndrome in Korean boys: a 3-y prospective cohort study. Am J Clin Nutr 2011, 93(1):19-26.

27. Papoutsakis C, Yannakoulia M, Ntalla I, Dedoussis GV: Metabolic syndrome in a Mediterranean pediatric cohort: prevalence using International Diabetes Federation-derived criteria and associations with adiponectin and leptin. Metabolism: clinical and experimental 2012, 61(2):140-145.

28. Calcaterra V, Amici MD, Klersy C, Torre C, Brizzi V, Scaglia F, Albanesi M, Albertini R, Allais B, Larizza D: Adiponectin, IL-10 and metabolic syndrome in obese children and adolescents. ACTA BIOMED 2009, 80:117-123.

29. Suárez-Ortegón MF, Ramírez-Vélez R, Mosquera M, Méndez F, Aguilar-de Plata C: Prevalence of metabolic syndrome in urban Colombian adolescents aged 10-16 years using three different pediatric definitions. J Trop Pediatr 2012. doi:10.1093/tropej/fms054.

30. Chen F, Wang Y, Shan X, Cheng H, Hou D, Zhao X, Wang T, Zhao D, Mi J: Association between childhood obesity and metabolic syndrome: Evidence from a large sample of Chinese children and adolescents. PLOS ONE 2012, 7(10):e47380.

31. de Armas MG G, Monereo-Megías S, Merino-Viveros M, Iglesias-Bolaños P Vega-Piñero B: Prevalencia de síndrome metabólico en una población de niños y adolescentes con obesidad. Endocrinol Nutr 2012, 59(3):155-159.

32. Juárez-López C, Klünder-Klünder M, Medina-Bravo P, Madrigal-Azcárate A, Mass-Díaz E, Flores-Huerta S: Insulin resistance and its association with the components of metabolic syndrome among obese children and adolescents. BMC Public Health 2010, 10(1):318.
33. Hindle A, Edwards C, McCaffrey T, Fu S, Brody F: Reactivation of adiponectin expression in obese patients after bariatric surgery. Surgical Endoscopy 2010, 24(6):1367-1373.

34. Cruz M, García-Macedo R, García-Valerio Y, Gutiérrez M, Medina-Navarro R, Durán G, Wacher N, Kumate J: Low adiponectin levels predict type 2 diabetes in Mexican children. Diabetes Care 2004, 27:1451-1453.

35. Daimon M, Oizumi T, Saitoh T, Kameda W, Hirata A, Yamaguchi H, Ohnuma $H$, lgarashi $M$, Tominaga $M$, Kato $T$ : Decreased serum levels of adiponectin are a risk factor for the progression to type 2 diabetes in the Japanese population. Diabetes Care 2003, 26(7):2015-2020.

36. Cook JR, Semple RK: Hypoadiponectinemia-Cause or Consequence of Human "Insulin Resistance"? J Clin Endocrinol Metab 2010, 95(4):1544-1554.

37. Medina-Bravo P, Meza-Santibáñez R, Rosas-Fernández P, Galván-Duarte R, Saucedo-García R, Velázquez-López L, Torres-Tamayo M: Decrease in serum adiponectin levels associated with visceral fat accumulation independent of pubertal stage in children and adolescents. Arch Med Res 2011, 42(2):115-121.

38. Rasmussen-Torvik LJ, Pankow JS, Jacobs DR Jr, Steinberger J, Moran AM, Sinaiko AR: Influence of waist on adiponectin and insulin sensitivity in adolescence. Obesity 2009, 17(1):156-161.

\section{doi:10.1186/1471-2458-13-88}

Cite this article as: Klünder-Klünder et al:: Adiponectin in eutrophic and obese children as a biomarker to predict metabolic syndrome and each of its components. BMC Public Health 2013 13:88.

\section{Submit your next manuscript to BioMed Central and take full advantage of:}

- Convenient online submission

- Thorough peer review

- No space constraints or color figure charges

- Immediate publication on acceptance

- Inclusion in PubMed, CAS, Scopus and Google Scholar

- Research which is freely available for redistribution 